University of Nebraska - Lincoln

DigitalCommons@University of Nebraska - Lincoln

Faculty Publications: Department of Entomology

2012

\title{
Comparative Toxicity of Acaricides to Honey Bee (Hymenoptera: Apidae) Workers and Queens
}

\author{
Lizette Dahlgren \\ University of Nebraska-Lincoln \\ Reed M. Johnson \\ Ohio State University, johnson.5005@osu.edu \\ Blair D. Siegfried \\ University of Nebraska-Lincoln, bsiegfried1@ufl.edu \\ Marion D. Ellis \\ University of Nebraska-Lincoln, mellis3@unl.edu
}

Follow this and additional works at: https://digitalcommons.unl.edu/entomologyfacpub

Part of the Entomology Commons

Dahlgren, Lizette; Johnson, Reed M.; Siegfried, Blair D.; and Ellis, Marion D., "Comparative Toxicity of Acaricides to Honey Bee (Hymenoptera: Apidae) Workers and Queens" (2012). Faculty Publications: Department of Entomology. 531.

https://digitalcommons.unl.edu/entomologyfacpub/531

This Article is brought to you for free and open access by the Entomology, Department of at DigitalCommons@University of Nebraska - Lincoln. It has been accepted for inclusion in Faculty Publications: Department of Entomology by an authorized administrator of DigitalCommons@University of Nebraska - Lincoln. 
Published in Journal of Economic Entomology 105:6 (2012), pp. 1895-1902; doi: 10.1603/EC12175 Copyright (C) 2012 Entomological Society of America; published by Oxford University Press. Used by permission.

Submitted May 1, 2012; accepted September 6, 2012.

\title{
Comparative Toxicity of Acaricides to Honey Bee (Hymenoptera: Apidae) Workers and Queens
}

\author{
Lizette Dahlgren, ${ }^{1}$ Reed M. Johnson, ${ }^{2}$ Blair D. Siegfried, ${ }^{1}$ \\ and Marion D. Ellis ${ }^{1}$
}

1. Department of Entomology, University of Nebraska-Lincoln, 103 Entomology Hall, Lincoln, Nebraska

2. Department of Entomology, The Ohio State University, Thorne Hall, 1680 Madison Ave., Wooster, Ohio

Corresponding author - Lizette Dahlgren, email lizette@huskers.unl.edu

\begin{abstract}
Acaricides are used to treat honey bee (Apis mellifera L.) colonies to control the varroa mite (Varroa destructor Anderson \& Trueman), a worldwide threat to honey bee health. Although acaricides control a serious honey bee parasite and mitigate bee loss, they may cause harm to bees as well. We topically applied five acaricides, each with a different mode of action, to young adult queen and worker bees to generate dose-response curves and LD50. Twenty-four hours after treatment, queens were found to be three times more tolerant of tau-fluvalinate and six times more tolerant of thymol than workers when adjusted for body weight differences between workers (108 mg) and queens (180 $\mathrm{mg})$. Queens survived the highest administered doses of fenpyroximate $(1620 \mu \mathrm{g} / \mathrm{g})$ and coumaphos $(2700 \mu \mathrm{g} / \mathrm{g})$ indicating that queens are at least 11-fold more tolerant of coumaphos and at least 54fold more tolerant of fenpyroximate than workers. However, queens treated with as little as $54 \mu \mathrm{g} / \mathrm{g}$ of fenpyroximate exhibited reduced survival over $6 \mathrm{wk}$ after treatment. Amitraz was the only acaricide tested for which queens were not more tolerant than workers. The striking difference in acaricide tolerance of queen and worker honey bees suggests physiological differences in how the two castes are affected by xenobiotics.
\end{abstract}


Keywords: Varroa destructor, pesticide, Apis mellifera, miticide, queen

The eusocial honey bee lives in a colony in which a single mated queen is mother to thousands of semisterile female workers. Genetically identical female eggs may develop into either a queen or a worker depending only on their diet. Queen and worker larvae receive different diets (Beetsma 1979), with queen larvae receiving a blend of larval food that includes the protein royalactin that results in a faster growth rate, larger body size, and increased ovary development (Reginato and Cruz-Lamdim 2003, Kamakura 2011). Adult workers and queens differ physiologically in their energetic and metabolic requirements, their susceptibility to pathogens, and the circulating proteins found in the hemolymph (Chan et al. 2006). Despite pronounced differences between the castes, there is little information on how queens and workers differ in their tolerance of pesticides in general, or to the in-hive acaricides used by beekeepers to control the ectoparasitic mite Varroa destructor Anderson \& Trueman.

The widespread distribution of Varroa mites poses a global threat to honey bee colony health (Sammataro et al. 2000). Varroa mites weaken the hive by consuming hemolymph from pupal and adult bees and by transmitting viruses that may increase colony susceptibility to both abiotic and biotic environmental stressors (Shen et al. 2005). Many honey bee colonies infested with Varroa mites perish without beekeeper intervention (Kraus and Page 1995, National Acad. of Sciences [NAS] 2007). While labor-intensive alternatives to chemical control exist (Sammataro et al. 2000, Charriére et al. 2003, Imdorf et al. 2003) many beekeepers rely on acaricides to protect their colonies. The widespread detection of acaricide residues in beeswax (Mullin et al. 2010) serves to demonstrate the widespread use of acaricides and indicates that the exposure of bees to these compounds may continue long after acaricide treatment has ceased.

Acaricides used to control Varroa include compounds with different modes of action including a cholinesterase inhibitor (coumaphos), a $\mathrm{Na}^{+}$channel agonist (tau-fluvalinate), an octopaminergic agonist (amitraz), and a mitochondrial electron transport inhibitor (fenpyroximate). Natural products have been successfully used as acaricides as well, such as blends of essential oils including the monoterpenoid thymol (Johnson et al. 2010) that acts as a GABA modulator in humans and flies (Drosophila melanogaster [Meigen] and Phaenicia sericata [Meigen]) (Priestley et al. 2003, Waliwitiya et al. 2010).

A vast majority of laboratory-based research on honey bee toxicology has been performed using worker bees, as mandated for pesticide registration requirements (U.S. Environmental Protection Agency 1996, Fischer and Moriarty 2011), with only a few studies examining the field effects of acaricide exposure on queens (Haarmann et al. 2002, Pettis et al. 2004). We sought to generate $L_{50}$ statistics for queens that would be comparable to those commonly generated for workers in laboratory assays using five different acaricides: amitraz, coumaphos, fenpyroximate, tau-fluvalinate, and thymol. Additionally, unmated treated queens were monitored for $6 \mathrm{wk}$ after treatment to assess the effects of single-dose acaricide exposure on queen longevity. 


\section{Materials and Methods}

Honey bee colonies and queen banks were located at the University of Nebraska-Lincoln East Campus (Lincoln, NE). The same colonies supplied larvae selected through grafting to become queens were used for rearing queen cells and supplied adult workers for parallel bioassays conducted from April through September 2010. All colonies were requeened in April 2010 with Italian queens obtained from C. F. Koehnen \& Sons, Inc., Glenn, California. Bacterial brood diseases and Nosema were prevented with oxytetracycline as Terramycin (Pfizer, New York) and fumagillin as Fumadil B (Medivet Pharmaceuticals, High River, Alberta, Canada) applied according to label instructions in March 2010. Thymol as Apiguard (Vita, Basingstoke, United Kingdom) and oxalic acid (Fischer Scientific, Rochester, New York) were the only acaricides used in the apiary to control Varroa populations during the 4 yr prior, with the last application in the fall of 2009.

Queens were reared using methods described by Doolittle (Laidlaw and Page 1997) in which individual 12-24 h old worker larvae were grafted into plastic cups (JZ BZ Base Mount Cell Cups, Mann Lake Supply, Ltd., Hackensack, Minnesota). Ripe capped queen cells were placed into queen confinement cages (QC-115, Mann Lake Supply) and a small drop of queen candy (1:1 honey and confectioners' sugar) was placed in the base of each individual cage to ensure that newly emerged virgins had access to food until they became attractive to workers $(\approx 4 \mathrm{~d})$. As many as 60 caged queen cells were placed in a queen bank to emerge. Queen banks consisted of four or five frame nucleus colonies stocked with $1 \mathrm{~kg}$ of worker bees (Laidlaw and Page 1997). Frames of larvae were added weekly to maintain colony strength and frames were inspected twice per week to remove any uncaged queen cells.

Worker bees were emerged from frames filled with late-stage capped brood in a dark $32-34^{\circ} \mathrm{C}$ incubator. Newly eclosed bees were brushed from frames daily and placed inside an 8-mesh screen-wooden cage $(15.25 \mathrm{~cm}: 10.15 \mathrm{~cm}: 17.75 \mathrm{~cm})$ (1:w:h). Caged worker bees were provided 1:1 sugar-water, stored in an incubator at $32-34^{\circ} \mathrm{C}$, and maintained for 3-4 $\mathrm{d}$ before pesticide application.

Technical grade chemicals were used for all trials. Amitraz, coumaphos, fenpyroximate, and tau-fluvalinate were purchased from Chem Services Inc. (West Chester, Pennsylvania). Thymol was purchased from Aldrich (Milwaukee, Wisconsin). ACS grade acetone (Fisher, Pittsburg, Pennsylvania) was used to dilute all chemicals and was applied to bees in pure form as a solvent control.

Bioassays were conducted using methods described by Johnson et al. 2006. A range of acaricide concentrations were made through serial dilutions in acetone on the day of treatment for queen bioassays, and up to a month prior, with storage at $-20^{\circ} \mathrm{C}$, for worker bioassays.

Queen bioassays were performed on a minimum of 15, 2- to 5-d old adult virgin queens removed from queen banks for no $>1 \mathrm{~h}$. Queens were briefly anesthetized with $\mathrm{CO}_{2}$ and treated topically on the thoracic notum in two $1 \mu \mathrm{l}$ applications using a $50 \mu \mathrm{l}$ syringe fitted to a repeating microapplicator (PB-600, Hamilton, Reno, Nevada). Controls were treated with two $1 \mu \mathrm{l}$ doses of acetone. When it was possible, acaricide treatment series included doses causing 0 and $100 \%$ mortality. Each treatment was replicated at least three times 
using queens from different source colonies for each treatment date. After treatment queens were weighed to the nearest milligram using an analytical balance (Sartorius AG R160P, Goettingen, Germany). Virgin queens were then placed back into the same emergence cage with a new cap (a brown cell cup; QC-110 Mann Lake Supply) and yellow cell cup holder (QC-125, Mann Lake Supply) and returned to a queen bank. Mortality was assessed at $24 \mathrm{~h}, 48 \mathrm{~h}$, and then every week for $6 \mathrm{wk}$ after treatment. Immobile queens were scored as dead and removed from queen banks.

Worker bioassays were conducted similarly to queens, but bees were treated with a single microliter of acaricide or acetone and were kept in groups of 17-23 inside wax-coated paper cups $\left(177 \mathrm{~cm}^{3}\right)$ covered with bleached cotton cheesecloth. Groups of bees were fed 1:1 sucrose-water in a punctured $1.5 \mathrm{ml}$ Eppendorf tube and returned to the incubator.

Acute mortality in both workers and queens, defined as mortality recorded at 24 or 48 $h$ after treatment, was analyzed by log-probit analysis in the $R$ statistical environment (The R Development Core Team 2010) with MASS libraries (Venables and Ripley 2002). Lethal dose (LD) values with 95\% CIs were calculated using Fieller's method with correction for heterogeneity where appropriate (Finney 1971). Treatment series with $>5 \%$ control mortality were removed from analyses. Fenpyroximate treatment was compared at the $48 \mathrm{~h}$ time point because of the relatively slow toxicity this compound shows in worker bees, while all other acaricides were compared at the $24 \mathrm{~h}$ time point.

A comparison of long-term queen survival of treated queens, using only those queens surviving beyond $48 \mathrm{~h}$, was performed against control queens by pairwise exact log rank tests using the "coin" library in R (Everitt and Hothorn 2006), which allow for comparisons between groups of different sizes. Significance cutoffs were corrected for multiple comparisons using the Bonferroni method.

\section{Results}

Toxicological statistics are reported as microgram toxin per gram of body weight to facilitate comparisons between castes with different masses (virgin queens $=180 \mathrm{mg}$ and workers $=108 \mathrm{mg}$ ). The relative toxicities of the five acaricides to workers were amitraz $>$ fenpyroximate $>$ tau-fluvalinate $>$ coumaphos $>$ thymol (Table 1). The relative toxicities of acaricides to queens were amitraz $>$ tau-fluvalinate $>$ thymol. No significant differences in mortality occurred between 24 and $48 \mathrm{~h}$ for each acaricide except fenpyroximate; therefore, only one value is reported in Table 1 for both workers and queens. Dose-response curves for queens could not be determined for fenpyroximate or coumaphos, as both compounds caused little mortality at 24 and $48 \mathrm{~h}$ time points at the highest doses that could be tested (1620 $\mu \mathrm{g} / \mathrm{g}$ for fenpyroximate and $2700 \mu \mathrm{g} / \mathrm{g}$ for coumaphos).

Twenty-four hours after exposure, queens were six times more tolerant of thymol and three times more tolerant of tau-fluvalinate than were workers (Table 1). Queens were at least 54 times more tolerant of fenpyroximate than workers, based on a comparison of the highest dose administered to queens and the $48 \mathrm{~h}$ worker LD50. Queens were at least 11 times more tolerant than workers of coumaphos based on the highest dose administered to queens and the $24 \mathrm{~h}$ worker $\mathrm{LD}_{50}$. No difference in susceptibility to amitraz was observed between queens and workers. 
Table 1. Contact acaricide toxicity to honey bee virgin queens and workers

\begin{tabular}{|c|c|c|c|c|c|c|c|c|c|c|c|c|c|c|}
\hline \multirow[b]{2}{*}{ Acaricide } & \multirow[b]{2}{*}{$\begin{array}{l}\text { Time } \\
\text { (hours) }\end{array}$} & \multicolumn{6}{|c|}{ Queen } & \multicolumn{6}{|c|}{ Worker $^{a}$} & \multirow{2}{*}{$\begin{array}{c}\text { Queen toxicity } \\
\text { relative to } \\
\text { worker }^{c}\end{array}$} \\
\hline & & $\begin{array}{l}\text { LD }_{50} \\
(\mu \mathrm{g} / \mathrm{g})\end{array}$ & $\mathrm{CI}^{b}$ & $N$ & slope \pm SE & $\chi^{2}$ & $\mathrm{df}$ & $\begin{array}{c}\mathrm{LD}_{50} \\
(\mu \mathrm{g} / \mathrm{g})\end{array}$ & $\mathrm{CI}^{b}$ & $N$ & slope \pm SE & $\chi^{2}$ & $\mathrm{df}$ & \\
\hline Amitraz & 24 & 21.8 & $(17.8-29.4)$ & 36 & $6.13 \pm 1.8$ & 0.6 & 1 & 26.7 & $(17.8-36.6)$ & 552 & $2.23 \pm 0.35$ & 26 & 7 & 0.816 \\
\hline Coumaphos & 24 & $>2700$ & & 14 & & & & 241 & $(181.0-366.0)$ & 283 & $4.27 \pm 0.83$ & 9.20 & 3 & $>11.2^{*}$ \\
\hline Fenpyroximate & 48 & $>1620$ & & 16 & & & & 30.0 & $(24.7-36.0)$ & 533 & $2.65 \pm 0.24$ & 9.59 & 6 & $>54.0^{*}$ \\
\hline Tau-fluvalinate & 24 & 586 & $(439-837)$ & 90 & $2.35 \pm 0.63$ & 3.54 & 4 & 188 & $(155-242)$ & 528 & $1.59 \pm 0.18$ & 4.71 & 5 & $3.11^{*}$ \\
\hline Thymol & 24 & 3240 & $(2680-4520)$ & 74 & $4.04 \pm 1.0$ & 1.41 & 2 & 524 & $(401-666)$ & 902 & $2.32 \pm 0.27$ & 34.18 & 8 & $6.18^{*}$ \\
\hline
\end{tabular}

Twenty-four and $48 \mathrm{~h} \mathrm{LD} 50$ for five acaricides to 2- to 5-d-old virgin queens and 3- to 4-d-old worker honey bees shown.

a. Worker data originates from within the same lab from the same source bees as queens throughout the summer 2010.

b. CIs (95\%) indicated with LD50 dose curve when possible.

c. Worker and queen LD50 with nonoverlapping CIs are considered significantly different as indicated with an asterisk (*). 
Kaplan-Meier survival estimates were plotted for each acaricide treatment level, as well as the control treatment for each group, with right-censoring of queens surviving beyond the 6-wk observation window (Fig. 1). No longevity data were collected for workers. Queens that had survived the initial $48 \mathrm{~h}$ after treatment with any dose of amitraz, coumaphos, or tau-fluvalinate were as likely as control-treated queens to survive to $6 \mathrm{wk}$ (Fig. $1 \mathrm{~A}-\mathrm{C})$. Queens receiving $2700 \mu \mathrm{g} / \mathrm{g}$ thymol were significantly less likely $(P<0.011)$ to survive from $48 \mathrm{~h}$ to $6 \mathrm{wk}$ than controls, but other doses did not significantly affect the longevity of queens (Fig. 1D). Queens receiving fenpyroximate at any dose level were as likely as control queens to survive to $48 \mathrm{~h}(P=0.17$; Fisher Exact Test). However, queens receiving any dose of fenpyroximate $>27 \mu \mathrm{g} / \mathrm{g}$ were significantly less likely than controls to survive the period from $48 \mathrm{~h}$ to $6 \mathrm{wk}$ ( $P<0.0071$; Exact Logrank Test) (Fig. 1E).

\section{Discussion}

This study showed that, when adjusted for differences in body weight, queens and workers differ substantially in their tolerance of most acaricides, with queens tolerating higher doses of coumaphos, fenpyroximate, thymol, and tau-fluvalinate. This is not the first time that queens have been found to be more tolerant of pesticides than workers: the queen $\mathrm{LD}_{50}$ for the organochlorine DDT was found to be 6.6 times higher than that of honey bee workers (Graves and Mackensen 1965). These acaricides are presumed to kill arthropods through different modes of action (Johnson et al. 2010) and yet queens were found to be more tolerant of all acaricides, except amitraz, suggesting that queens possess a nonspecific mechanism of acaricide tolerance.

In contrast to all other acaricides tested, queens and workers tolerate equal amounts of amitraz, indicating that any mechanism of nonspecific pesticide tolerance with which queens are endowed is not effective against this compound. Amitraz is an octopaminergic agonist in most arthropods. Octopamine is important for honey bee dance language (Barron et al. 2007), division of labor (Schulz and Robinson 2001, Barron and Robinson 2005), and kin recognition (Robinson et al. 1999), yet there are no reports that the use of amitraz as an acaricide alters social behavior in bees. The mode of action of amitraz against honey bees is unknown, however, amitraz has been shown to increase the frequency of cell death in larval midgut cells (Gregorc and Bowen 2000, Gregorc and Ellis 2011). In addition, unlike most insecticides that possess an ester bond, amitraz has been suggested to be bioactivated by hydrolysis (Schuntner and Thompson 1978, Knowles and Gayden 1983). As a consequence, differences in hydrolytic enzyme activity between queen and worker castes may contribute to differential sensitivity among the compounds tested. Nonspecific mechanisms of pesticide tolerance may include nutritional state, sequestration, detoxification and clearance, or tolerance of pesticide induced stress. Each possibility is explored in the next few paragraphs. 

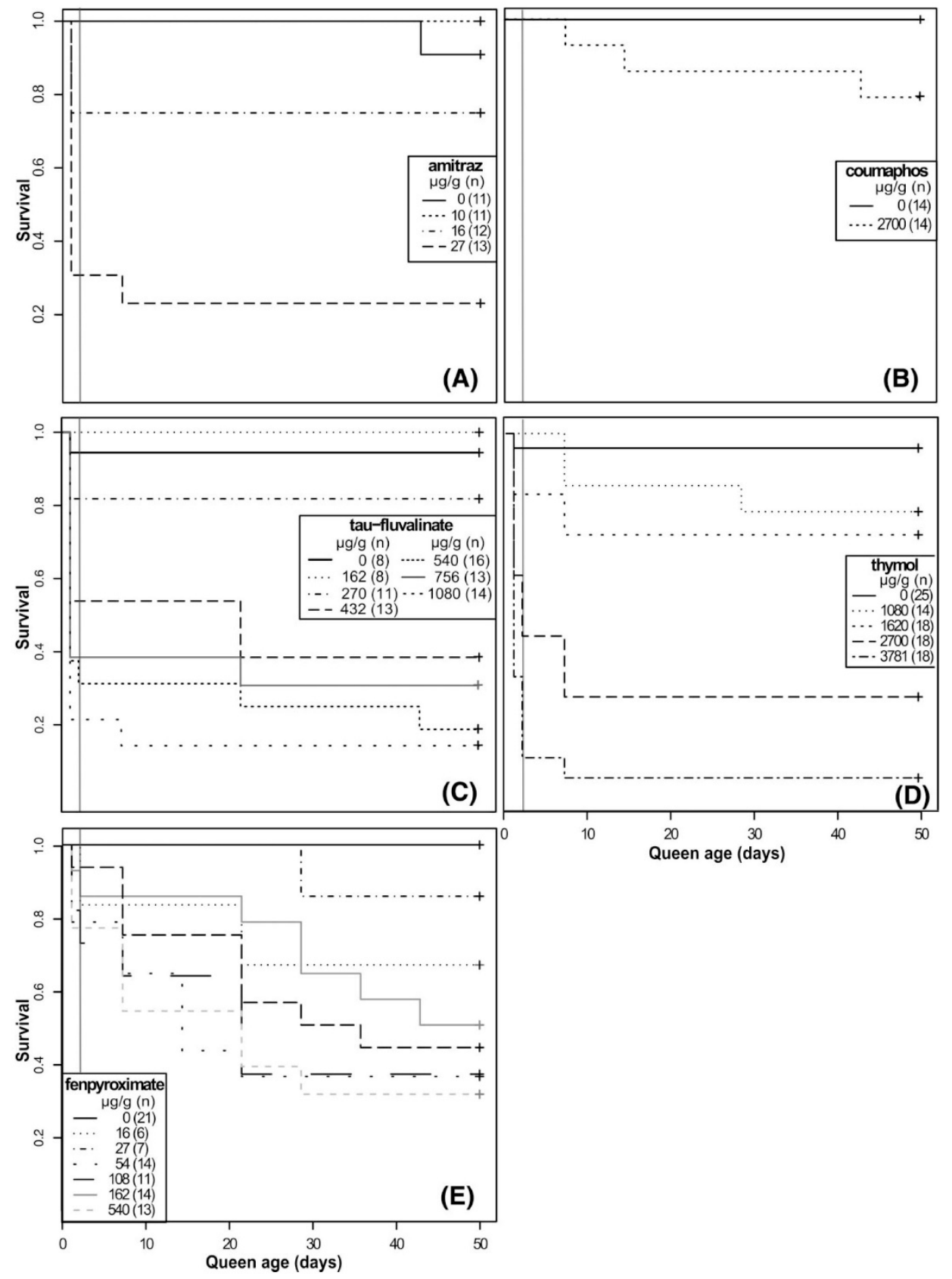

Figure 1. Kaplan-Meier survival curves for five acaricides applied to 3-d-old virgin queen honey bees. Acaricides included (A) amitraz, (B) coumaphos, (C) tau-fluvalinate, (D) fenpyroximate, and (E) thymol. Vertical lines indicate the $48 \mathrm{~h}$ timepoint. Line styles represent queen mortality for acaricide dose $(\mu \mathrm{g} / \mathrm{g})$. The number of queens treated for each dose is given in parentheses after the dose in $\mu \mathrm{g} / \mathrm{g}$. In general, mortality increased with increased acaricide dose except when treated with (D) fenpyroximate. 
Feeding on high quality pollen from diverse plant sources is known to decrease the susceptibility of adult bees to pesticides (Wahl and Ulm 1983) and diseases (Alaux et al. 2010). Some of the difference between workers' and queens' susceptibility to acaricides may be because workers in this experiment were maintained in an incubator, without access to any protein source, while queens were maintained in queen banks and were likely fed protein by attending worker bees. Thus, the superior queen adult diet may be responsible for some of the reduced acaricide susceptibility observed in queens.

In insects, the fat body serves many vital functions (Arrese and Soulages 2010) and it is therefore not surprising that longevity mechanisms occur within the fat body (Hwangbo et al. 2004). Winter worker bees have greater dry weight, protein, and fat content (Kunert and Crailsheim 1988) and live significantly longer (3-5 mo) than summer workers ( $\approx 30 \mathrm{~d}$ ). Queens, which can live several years, are generally more tolerant of acaricides, and it is possible that queens have greater capacity to sequester or metabolize these acaricides. The insect fat body functions in insect immune response and is analogous to the mammalian liver and adipose tissue (Canavoso et al. 2001), serving functions of xenobiotic metabolism, sequestration, and energy storage.

Nonspecific mechanisms that may allow queens to tolerate higher levels of coumaphos, tau-fluvalinate, thymol, and fenpyroximate may be elucidated through finding similarities in how these compounds are managed in vivo in honey bees. Coumaphos, tau-fluvalinate, and possibly thymol all upregulate cytochrome P450 genes within the honey bee (Mao et al. 2011, Boncristiani et al. 2012). Coumaphos is an organophosphate. Organophosphates as a class of insecticides are dependent on cytochrome P450s for activation. Johnson et al. (2009) suggested that both coumaphos and tau-fluvalinate are detoxified by cytochrome P450 and carboxylesterases in honey bees. Using heterologously expressed honey bee cytochrome P450s, Mao et al. (2011) found both coumaphos and tau-fluvalinate are indeed metabolized. In insects, cytochrome P450s are expressed in the midgut, fat body, Malpighian tubules, nervous tissue, corpora allata, glands, and antennae with the midgut often expressing the highest level of activity. There are at least three midgut cytochrome P450 enzymes responsible for the detoxification reactions catalyzed in workers: CYP9Q1, CYP9Q2, and CYP9Q3 (Mao et al. 2011). CYP6S14 upregulation was triggered in workers by thymol treatment with Apistan (Boncristiani et al. 2012). Cockroaches have been demonstrated to have age-dependent changes in levels of cytochrome P450s (Turnquist and Brindley 1975). Paralleling this hypothesis, Valles et al. (1994 and 1996), demonstrated that male cockroaches were more susceptible to insecticides than older male and female nymphs. Adult males were found to have decreased cytochrome P450 content and methoxyresorufin O-demethylase and ethoxyresorufin O-deethylasein activities in comparison with the more tolerant nymphs (Valles et al. 1996). Likewise, it is possible that bees could have caste-dependent changes in levels of cytochrome P450s, with queens having higher titers than workers.

Finally, differences between queen and worker tolerance may be because of a greater tolerance of pesticide-induced stress. Honey bee queens have been shown to tolerate higher levels of pesticide-induced oxidative stress than worker bees (Corona et al. 2007). One potential commonality between coumaphos, tau-fluvalinte, fenpyroximate, and thy- 
mol is that all may cause oxidative stress. Oxidative stress induced by pesticides is characterized by oxygen free radical formation, induction of cytochrome P450s, alteration in antioxidant enzymes, and a glutathione redox system (Banerjee et al. 2001). Therefore, one hypothesis is that queens are able to tolerate greater amounts of each of these pesticides because of their intrinsic ability to tolerate higher levels of reactive oxygen species.

The ability for queens to tolerate greater oxidative stress than workers may come from differences in the fatty acid composition of their respective membranes (Haddad et al. 2007). Newly emerged workers and queens, which have less polyunsaturated and more monounsaturated fatty acids, were found to be more resistant to peroxidation than other workers (Haddad et al. 2007). Monounsaturated phospholipids are less susceptible to peroxidation than polyunsaturated phospholipids. It may be that queens maintain a low ratio of peroxidation-susceptible polyunsaturated fats throughout life through consumption of a filtered diet of jelly, which has been shown to contain little to no polyunsaturated fats, provided to them by workers (Haddad et al. 2007).

As postulated by Amdam and Omholt (2002), it is possible that vitellogenin plays a role in the tolerance of xenobiotics. Worker lifespan is known to be influenced by the synthesis of vitellogenin, a glyco-lipoprotein produced in the fat body (Seehuus et al. 2006). Vitellogenin is a female-specific yolk precursor in many oviparous species that functions in honey bees in brood food production (Seehuus et al. 2007), regulation of foraging behavior, longevity independent of behavior (Nelson et al. 2007), as an antioxidant (Seehuus et al. 2006) and in enhancing innate immunity (Amdam et al. 2004, 2005). Vitellogenin has been shown to affect adult longevity of both queens and workers (Amdam et al. 2009), partially because of its free-radical scavenging capacity (Seehuus et al. 2006). In addition, vitellogenin composes up to $50 \%$ of the total hemolymph protein in queens (Engels et al. 1990), a 20-fold higher concentration than in summer workers (Engels et al. 1990, Corona et al. 2007). If acaricide exposure causes oxidative stress in bees, as pesticide exposure does in mammals (Abdollahi et al. 2004), then the greater tolerance to acaricides exhibited by queens may be mediated by the antioxidant capacity of vitellogenin.

Fenpyroximate administered at doses as high as $2,700 \mu \mathrm{g} / \mathrm{g}$ caused little mortality in queens observed for $48 \mathrm{~h}$. However, fenpyroximate treatment at doses as low as $54 \mu \mathrm{g} / \mathrm{g}$, or $9.7 \mu \mathrm{g} /$ queen, caused a significant reduction in queen survival over the subsequent 6 wk. This acaricide functions as an inhibitor of energy metabolism in the mitochondria through interactions with complex I (Motoba et al. 2000). In mammalian neuroblastoma cells, fenpyroximate and other complex I mitochondrial inhibitors cause ATP depletion, and cell death, possibly through generation of reactive oxygen species (Sherer et al. 2007). The effects of fenpyroximate on queen longevity is of particular practical concern as it is quite plausible that queens could encounter fenpyroximate at this level if the formulated product, Hivastan, which contains $67.5 \mathrm{mg}$ fenpyroximate in a patty formulation, is used.

Finally, clues to the high xenobiotic tolerance of queens as compared with workers may be elucidated through comparing gene expression between the two castes. To date, there are many genes of unknown function that are upregulated in queen castes of hymenoptera. Here we discuss those genes with known or hypothesized functions. Studies comparing gene expression between worker and queen castes have found multiple upregulated genes in queens associated with oxidative pathways, mitochondrial genes, and insulin signaling 
(Grozinger et al. 2007). Honey bee larval studies showed queens express significantly higher Locus 1CB6, including hexamerins and arylphorins (Evans and Wheeler 1999) and increased AmIF-2mt mRNA, suggesting increased mitochondrial translation in queens (Corona et al. 1999). Honey bee caste gene family expression differences included oxidoreductases (metabolism), peptidases (immune function), mitochondria (metabolism), and defensins (immune function) (Grozinger et al. 2007). Studies comparing gene expression between worker and queen castes in ants found significant upregulation in queen genes hypothesized to be involved with immune defense (Graff et al. 2007); however, this was not the case in bumble bees (Pereboom et al. 2005). Pereboom et al. 2005 did find significant upregulation of electron transport genes in queens. Apparently absent from all of these findings are genes encoding detoxification functions, which may indicate that the mechanism of queen tolerance is not linked to the capacity of carboxylesterases or cytochrome P450s.

Understanding the differences in how queens and workers respond to toxins may facilitate the design and discovery of acaricides that are tolerated by bees. Reciprocally, it may also provide insight into target traits for selecting bees that are better able to tolerate exposure to toxins. The assessment of the response of individual virgin queens to toxicants requires more time and resources than assessing worker bee responses but is still far easier than assessing queen survival in a whole-colony setting. Our results indicate that this is a valuable field of inquiry and will likely increase our understanding of molecular, metabolic, and endocrine processes of how honey bees and social insects deal with chemical stressors in their environment. The increased understanding of pesticide interactions within the honey bee may also lead to alleviation of current health problems seen in honey bees around the world.

Acknowledgments - The authors thank Bill McCormick for designing much of the beekeeping and queen rearing equipment. They also wish to acknowledge Reneé Berger, Ginny Morgal, Akinwande Kayode, and Bethany Teeters for assistance with laboratory bioassays and rearing and maintaining queens in the field. The authors sincerely appreciate the suggestions of the Hebets, Bosolo, and Wagner labs of the University of Nebraska-Lincoln Biology Department in reviewing a draft of this manuscript. This work was funded by the U.S. Department of Agriculture Managed Pollinator Coordinated Agriculture Project grant to investigate factors affecting honey bee health.

\section{References Cited}

Abdollahi, M., A. Ranjbar, S. Shadnia, S. Nikfar, and A. Rezaie. 2004. Pesticides and oxidative stress: a review. Med. Sci. Monitor 10: RA141-RA147.

Alaux, C., F. Ducloz, D. Crauser, and Y. LeConte. 2010. Diet effects on honeybee immunocompetence. Biol. Lett. 6: 562-565.

Amdam, G. V., and S. W. Omholt. 2002. The regulatory anatomy of honeybee lifespan. J. Theor. Biol. 216: 209-228.

Amdam, G. V., A.L.T.O. Aase, S.-C. Seehuus, M. K. Fondrk, K. Norberg, and K. Hartfelder. 2005. Social reversal of immunosenescence in honey bee workers. Exp. Gerontol. 40: 939-947. 
Amdam, G. V., O. Rueppell, M. K. Fondrka, R. E. Page, and C. M. Nelson. 2009. The nurse's load: early-life exposure to brood-rearing affects behavior and lifespan in honey bees (Apis mellifera). Exp. Gerontol. 44: 467-471.

Amdam, G. V., Z.L.P. Simões, A. Hagen, K. Norberg, K. Schrøder, Ø. Mikkelsen, T.B.L. Kirkwood, and S. W. Omholt. 2004. Hormonal control of the yolk precursor vitellogenin regulates immune function and longevity in honeybees. Exp. Gerontol. 39: 767-773.

Arrese, E. L., and J. L. Soulages. 2010. Insect fat body: energy, metabolism, and regulation. Annu. Rev. Entomol. 55: 207-225.

Banerjee, B. D., V. Seth, and R. S. Ahmed. 2001. Pesticide-induced oxidative stress: perspective and trends. Rev. Environ. Health 16: 1-40.

Barron, A. B., and G. E. Robinson. 2005. Selective modulation of task performance by octopamine in honey bee (Apis mellifera) division of labour. J. Comp. Physiol. A. 191: 659-668.

Barron, A. B., R. Maleszka, R. K. Vander Meer, and G. E. Robinson. 2007. Octopamine modulates honey bee dance behavior. Proc. Natl. Acad. Sci. U.S.A. 104: 1703-1707.

Beetsma, J. 1979. The process of queen worker differentiation in the honey bee. Bee World 60: 24-39.

Boncristiani, H., R. Underwood, R. Schwarz, J. D. Evans, J. Pettis, and D. vanEngelsdorp. 2012. Direct effect of acaricides on pathogen loads and gene expression levels of honey bee Apis mellifera. J. Insect Physiol. 58: 613-620.

Canavoso, L. E., Z. E. Jouni, K. J. Karnas, J. E. Pennington, and M. A. Wells. 2001. Fat metabolism in insects. Annu. Rev. Nutr. 21: 23-46.

Chan, Q.W.T., C. G. Howes, and L. J. Foster. 2006. Quantitative comparison of caste differences in honeybee hemolymph. Mol. Cell Proteomics 5: 2252-2262.

Charriére, J.-D., A. Imdorf, B. Bachofen, and A. Tschan. 2003. The removal of capped drone brood: an effective means of reducing the infestation of varroa in honey bee colonies. Bee World 84: 117124.

Corona, M., E. Estrada, and M. Zurita. 1999. Differential expression of mitochondrial genes between queens and workers during caste determination in the honeybee, Apis mellifera. J. Exp. Biol. 202: 929-938.

Corona, M., R. A. Velarde, S. Remolina, A. Moran-Lauter, Y. Wang, K. A. Hughes, and G. E. Robinson. 2007. Vitellogenin, juvenile hormone, insulin signaling, and queen honey bee longevity. Proc. Natl. Acad. Sci. U.S.A. 104: 7128-7133.

Engels, W., H. Kaatz, A. Zillikens, Z.L.P. Simoes, A. Trube, R. Braun, and F. Dittrich. 1990. Honey bee reproduction: vitellogenin and caste-specific regulation of fertility. Adv. Invert. Rep. 5: 494-502.

Evans, J. D., and D. E. Wheeler. 1999. Differential gene expression between developing queens and workers in the honey bee, Apis mellifera. Proc. Natl. Acad. Sci. U.S.A. 96: 5575-5580.

Everitt, B. S., and T. Hothorn. 2006. A handbook of statistical analyses using R, 1st ed. Chapman \& Hall/CRC, Boca Raton, FL.

Finney, D. J. 1971. Probit analysis, 3rd ed. Cambridge University Press, New York, NY.

Fischer, D., and T. Moriarty. 2011. Pesticide risk assessment for pollinators: summary of a SETAC Pellston Workshop. Society of Environmental Toxicology and Chemistry (SETAC), Pensacola, FL.

Graff, J., S. Jemielity, J. D. Parker, K. M. Parker, and L. Keller. 2007. Differential gene expression between adult queens and workers in the ant Lasius niger. Mol. Ecol. 16: 675-683.

Graves, J. B., and O. Mackensen. 1965. Topical application and insecticide resistance studies on the honey bee. J. Econ. Entomol. 58: 990-993. 
Gregorc, G. A., and J. D. Ellis. 2011. Cell death localization in situ in laboratory reared honey bee (Apis mellifera L.) larvae treated with pesticides. Pestic. Biochem. Phys. 99: 200-207.

Gregorc, G. A., and I. D. Bowen. 2000. Histochemical characterization of cell death in honeybee larvae midgut after treatment with Paenibacillus larvae, amitraz, and oxytetracycline. Cell Biol. Int. 24: 319-324.

Grozinger, C. M., Y. Fan, S.E.R. Hoover, and M. L. Winston. 2007. Genome-wide analysis reveals differences in brain gene expression patterns associated with caste and reproductive status in honey bees (Apis mellifera). Mol. Ecol. 16: 4837-4848.

Haarmann, T., M. Spivak, D. Weaver, B. Weaver, and T. Glenn. 2002. Effects of fluvalinate and coumaphos on queen honey bees (Hymenoptera: Apidae) in two commercial queen rearing operations. J. Econ. Entomol. 95: 28-35.

Haddad, L. S., L. Kelbert, and A. J. Hulbert. 2007. Extended longevity of queen honey bees compared to workers is associated with peroxidation-resistant membranes. Exp. Gerontol. 42: 601-609.

Hwangbo, D. S., B. Gersham, M. P. Tu, M. Palmer, and M. Tatar. 2004. Drosophila dFOXO controls lifespan and regulates insulin signaling in the brain and fat body. Nature 429: 562-566.

Imdorf, A., J.-D. Charriére, V. Kilchenmann, S. Bogdanov, and P. Fluri. 2003. Alternative strategy in central Europe for the control of Varroa destructor in honey bee colonies. Apiacta 38: 258-285.

Johnson, R. M., Z. Wen, M. A. Schuler, and M. R. Berenbaum. 2006. Mediation of pyrethroid insecticide toxicity to honey bees (Hymenoptera: Apidae) by Cytochrome P450 Monooxygenases. J. Econ. Entomol. 99: 1046-1050.

Johnson, R. M., H. S. Pollock, and M. R. Berenbaum. 2009. Synergistic interactions between in-hive miticides in Apis mellifera. J. Econ. Entomol. 102: 474-479.

Johnson, R. M., M. D. Ellis, C. A. Mullin, and M. Frazier. 2010. Pesticides and honey bee toxicity. Apidologie 41: 312-331.

Kamakura, M. 2011. Royalactin induces queen differentiation in honeybees. Nature 473: 478-483.

Knowles, C. O., and A. K. Gayden. 1983. Penetration, metabolism, and elimination of Amitraz and $\mathrm{N}$-(2,4-Dimethylphenyl)-N-methylformamidine in southwestern corn borer larvae (Lepidoptera: Pyralidae). J. Econ. Entomol. 76: 410-413.

Kraus, B., and R. E. Page. 1995. Effect of Varroa jacobsoni (Mesostigmata: Varroidae) on feral Apis mellifera (Hymenoptera: Apidae) in California. Environ. Entomol. 24: 1473-1480.

Kunert, K., and K. Crailsheim. 1988. Seasonal changes in carbohydrate, lipid and protein content in emerging worker honeybees and their mortality. J. Apic. Res. 27: 13-21.

Laidlaw, H. H., and R. E. Page, Jr. 1997. Queen rearing and bee breeding. Wicwas Press, Cheshire, CT.

Mao, W., M. A. Schuler, and M. R. Berenbaum. 2011. CYP9Q-mediated detoxification of acaricides in the honey bee (Apis mellifera). Proc. Natl. Acad. Sci. U.S.A. 108: 12657-12662.

Motoba, K., H. Nishizawa, T. Suzuki, H. Hamaguchi, M. Uchida, and S. Funayama. 2000. Speciesspecific detoxification metabolism of fenpyroximate, a potent acaricide. Pestic. Biochem. Phys. 67: 73-84.

Mullin, C. A., M. Frazier, J. L. Frazier, S. Ashcraft, R. Simonds, D. vanEngelsdorp, and J. S. Pettis. 2010. High levels of miticides and agrochemicals in North American apiaries: implications for honey bee health. PLoS One 5: e9754.

(NAS) National Acad. of Sciences. 2007. Status of pollinators in North America. National Acad. Press, Washington, DC. 
Nelson, C. M., K. E. Ihle, M. K. Fondrk, R. E. Page, Jr., and G. V. Amdam. 2007. The gene vitellogenin has multiple coordinating effects on social organization. PLoS Biol. 5: 0673-0677.

Pereboom, J.J.M., W. C. Jordan, S. Sumner, R. L. Hammond, and A.F.G. Bourke. 2005. Differential gene expression in queen-worker caste determination in bumble-bees. Proc. R. Soc. B. 272: 11451152.

Pettis, J. S., A. M. Collins, R. Wilbanks, and M. F. Feldlaufer. 2004. Effects of coumaphos on queen rearing in the honey bee, Apis mellifera L. Apidologie 35: 605-610.

Priestley, C. M., E. M. Williamson, K. A. Wafford, and D. B. Sattelle. 2003. Thymol, a constituent of thyme essential oil, is a positive allosteric modulator of human GABA(A) receptors and a homooligomeric GABA receptor from Drosophila melanogaster. Br. J. Pharmacol. 140: 1363-1372.

Reginato, R. D., and C. Cruz-Lamdim. 2003. Ovarian growth during larval development of queen and worker of Apis mellifera (Hymenoptera: Apidae): a morphometric and histological study. Braz. J. Biol. 63: 121-127.

Robinson, G. E., L. M. Heuser, Y. LeConte, F. Lenquette, and R. M. Hollingworth. 1999. Neurochemicals aid bee nest-mate recognition. Nature 399: 534-535.

Sammataro, D., U. Gerson, and G. Needham. 2000. Parasitic mites of honey bees: life history, implications, and impact. Annu. Rev. Entomol. 45: 519-598.

Schulz, D. J., and G. E. Robinson. 2001. Octopamine influences division of labor in honey bee colonies. J. Comp. Physiol. A. 187: 53-61.

Schuntner, C. A., and P. G. Thompson. 1978. Metabolism of $\left[{ }^{14} \mathrm{C}\right]$ amitraz in larvae of Boophilus microplus. Aust. J. Biol. Sci. 31: 141-148.

Seehuus, S.-C., K. Norberg, T. Krekling, K. Fondrk, and G. V. Amdam. 2007. Immunogold localization of vitellogenin in the ovaries, hypopharyngeal glands and head fat bodies of honeybee workers, Apis mellifera. J. Insect. Sci. 7: 1-14.

Seehuus, S.-C., K. Norberg, U. Gimsa, T. Krekling, and G. V. Amdam. 2006. Reproductive protein protects functionally sterile honey bee workers from oxidative stress. Proc. Natl. Acad. Sci. U.S.A. 103: 962-967.

Shen, M., Y. Xiaolong, D. Cox-Foster, and L. Cui. 2005. The role of varroa mites in infections of Kashmir bee virus (KBV) and deformed wing virus (DWV) in honey bees. Virology 342: 141-149.

Sherer, T. B., J. R. Richardson, C. M. Testa, B. B. Seo, A. V. Panov, T. Yagi, A. Matsuno-Yagi, G. W. Miller, and J. T. Greenamyre. 2007. Mechanism of toxicity of pesticides acting at complex I: relevance to environmental etiologies of Parkinson's disease. J. Neurochem. 100: 1469-1479.

The R Development Core Team. 2010. R: a language and environment for statistical computing, version 2.11.1 (2010-05-31). R Foundation for Statistical Computing, Vienna, Austria.

Turnquist, R. L., and W. A. Brindley. 1975. Microsomal oxidase activities in relation to age and chlorcyclizine induction in American cockroach, Periplaneta americana fat body, midgut and hindgut. Pestic. Biochem. Phys. 5: 211-220.

U.S. Environmental Protection Agency. 1996. Ecological effects test guidelines OPPTS 850.3020 honey bee acute contact toxicity. EPA 712-C-96-147.

Valles, S. M., S. J. Yu, and P. G. Koehler. 1994. Detoxifying enzymes in adults and nymphs of the German cockroach: evidence for different microsomal monooxygenase systems. Pestic. Biochem. Phys. 49: 183-190.

Valles, S. M., S. J. Yu, and P. G. Koehler. 1996. Biochemical mechanisms responsible for stagedependent propoxur tolerance in the German cockroach. Pestic. Biochem. Physiol. 54: 172-180. 
Venables, W. N., and B. O. Ripley. 2002. Modern applied statistics with S, 4th ed. Springer, New York, NY.

Wahl, O., and K. Ulm. 1983. Influence of pollen feeding and physiological condition on pesticide sensitivity of the honey bee Apis mellifera carnica. Oecologia 59: 106-128.

Waliwitiya, R., P. Belton, R. A. Nicholson, and C. A. Lowenberger. 2010. Effects of the essential oil constituent thymol and other neuroactive chemicals on flight motor activity and wing beat frequency in the blowfly Phaenicia sericata. Pest Manage. Sci. 66: 277-289. 